Original Article (short paper)

\title{
Assessment of the external load of amateur soccer players during four consecutive training microcycles in relation to the external load during the official match
}

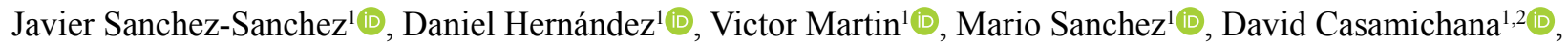 \\ Alejandro Rodriguez-Fernandez ${ }^{1,3}$, Rodrigo Ramirez-Campillo, ${ }^{1,4}$, Fabio Y. Nakamura ${ }^{1,5}$ \\ ${ }^{1}$ Universidad Pontificia de Salamanca, Research Group Planning and Assessment of Training and Athletic Performance, \\ Salamanca, Castilla y Leon, Spain; ${ }^{2}$ Universidad Europea del Atlantico, Santander, Cantabria, Spain; ${ }^{3}$ Universidad \\ Isabel I de Castilla, Burgos, Castilla y Leon, Spain; ${ }^{4}$ Laboratory of Human Performance. Quality of Life and Wellness \\ Research Group. Department of Physical Activity Sciences. Universidad de Los Lagos. Osorno, Chile; ${ }^{5}$ Universidade \\ Federal da Paraiba, UFPB, Associate Graduate Program in Physical Education, UPE, João Pessoa, PB, Brazil
}

\begin{abstract}
Aim: The aim of this study was to assess the external load of amateur male players during 4 consecutive training microcycles $(\mathrm{M})$ at the beginning of the in-season according to the training session in absolute external load demands and in relation to the competition demands. Methods: Regional-level players ( $\mathrm{n}=10$; age, $20.8 \pm$ 1.7 years; height, $175.5 \pm 3.8 \mathrm{~cm}$; body mass, $69.7 \pm 2.9 \mathrm{~kg}$; soccer experience, $13.2 \pm 2.5$ years) were monitored using GPS devices during training sessions and matches. The external load variables measured were: duration (min); total distance covered (TD); distance covered at high-speed (HID, 14.4-19.8 km/h); distance covered at sprinting $(\mathrm{SPD} ;>19.8 \mathrm{~km} / \mathrm{h})$; and distance covered in high intensity acceleration $\left(\mathrm{ACD} ;>2.5 \mathrm{~m} / \mathrm{s}^{2}\right)$ and deceleration (DECD; $<-2.5 \mathrm{~m} / \mathrm{s}^{2}$ ). Results: The results indicated that the external load variables (time, HID, SPD, ACD, and DECD) were similar between the four microcycles. Greater $(\mathrm{p}<0.01)$ time, TD, HID and SPD were observed in match day (MD)-2 compared to MD+1, MD-3, and MD-1. Aside from training duration, all external loads variables (TD, HID, $\mathrm{SPD}, \mathrm{ACD}$, and DECD) were lower during training sessions compared to official matches $(\mathrm{p}<0.05)$. Conclusion: Amateur soccer players present relative stable external training loads across competitive microcycles, with the peak load observed two days before the official match. Besides this, the match constitutes the highest load during a typical competitive microcycle in this cohort of players.
\end{abstract}

Keywords: football; match analysis; physiology of soccer; team sport; sports periodization.

\section{Introduction}

Soccer is a sport that demands high-intensity movements, such as sprints, acceleration, deceleration, and changes in direction ${ }^{1}$. These high-intensity movements may lead to fatigue when repeated throughout the match duration ${ }^{2}$. Therefore, training programs should aim to improve the ability to tolerate and repeat such high-intensity movements ${ }^{3}$, especially when combined with key tactical actions $\mathrm{s}^{4}$. The monitoring of training and competitive loads may help coaches and athletes in the programming to improve specific physical fitness ${ }^{5}$ and reduce injury risk ${ }^{6}$.

The technological advancements have facilitated access to several tools that may help coaches to assess training and competitive loads ${ }^{7}$. Training loads can be assessed by measuring physical and physiological variables, deemed to represent the internal load, and may also be quantified by measuring the external load (e.g., total distance, accelerations $)^{8}$. The internal load in soccer is usually assessed by measuring heart rate ${ }^{9}$ and rating of perceived exertion (RPE) ${ }^{10}$. However, the validity of heart rate is questionable during intermittent activities that involve a high anaerobic metabolic component ${ }^{11}$ and RPE seems to be not sensitive to high-speed actions that are carried out during training and/or matches ${ }^{12}$. For this reason, soccer technical staffs tend to prefer external load measures in order to assess training and match demands, and therefore the use of global positioning systems (GPS) has gained popularity as measuring tool ${ }^{6}$. The GPS offers the possibility to quantify velocity, acceleration, distance and player's movement patterns ${ }^{8}$. However, the measurement of common movements in soccer such as changes of direction and short displacements at high-velocity should be performed with caution ${ }^{13}$, especially when GPS units have a low sampling frequency (e.g., $1 \mathrm{~Hz}$ compared to $10 \mathrm{~Hz})^{14}$.

In recent years, there has been an increase in the number of studies reporting the external loads of high-level soccer players during training ${ }^{15,16}$, and some even have compared the external load during training with that measured during matches ${ }^{17,18}$. Of note, in one of the aforementioned studies, the external load (i.e., total distance, high-intensity distance, sprint distance and average speed) was measured during 6 consecutive in-season training microcycles (i.e., 1 microcycle $=1$ week) in professional soccer players, with no significant variations observed across the 6 microcycles ${ }^{16}$. However, when the external load was compared 
across training sessions within a competitive microcycle, Owen, Lago-Peñas, Gómez, Mendes, Dellal ${ }^{16}$ found lower GPS-derived external load near the competition day compared with the other training days. Similarly, in soccer players from the English Premier League, a greater external load was observed on the second day of training compared to the training day before competition for a given microcycle ${ }^{18}$. Another study ${ }^{15}$ reported that, aside from the distance covered at high velocity $(>5.5 \mathrm{~m} / \mathrm{s})$, other external load variables were lower during the training session before an official match when compared to previous training sessions more distant to the match day. This microcycle dynamics may be necessary to induce optimal physiological and performance recovery before competition ${ }^{16,17}$, in a similar fashion to the responses obtained during taper in other sports ${ }^{19}$.

However, a generalization of these findings is not recommended $^{18}$, especially to athletes of different competitive levels. In this sense, studies with amateur soccer players are lacking. Considering that amateur soccer is rising in popularity across the globe, with millions of new practitioners in recent years $^{20}$, it is of paramount importance to conduct more research with such a population. The periodization training model in team sports is often determined by the manager or coach, so that using GPS monitoring to identify any inappropriate training load progressions as well as to educate coaches on more suitable alternatives are crucial ${ }^{21,22}$. For this reason, knowing how nonprofessional teams organize their weekly training loads can be useful to practitioners. Therefore, the aim of this study was to assess the external load of amateur players during 4 consecutive training microcycles and their corresponding training sessions, in relation to the external load during competition. We tested the hypothesis that the external loads will be similar between different microcycles. In addition, we tested the hypothesis that the external loads will be lower during sessions near competition compared to previous training sessions within a given microcycle.

\section{Methods}

\section{Participants}

Regional-level male amateur players ( $\mathrm{n}=10$; age, $20.8 \pm 1.7$ years; height, $175.5 \pm 3.8 \mathrm{~cm}$; body mass, $69.7 \pm 2.9 \mathrm{~kg}$; soccer experience, $13.2 \pm 2.5$ years) participated in this study. Players regularly completed four 75-100 minute training sessions per week, plus an official match on weekends. During the study period, 4 official matches were played, 2 at home (5-1 and 2-1) and 2 as visitors (3-1 and 0-2), always played with a 1-4-4-2 tactical formation. To be included in the study, players were asked to complete all the 16 training sessions and to complete $\geq 65$ minutes of play during each of the 4 official competitive matches ${ }^{18}$. A total of 184 recordings were obtained associated with 160 training sessions and 24 matches. Data were obtained from 2 fullbacks, 2 central defenders, 2 midfielders, 2 widemidfielders, and 2 forwards. The athletes were fully informed about the aims of the study, the procedures involved, and the potential risks and the benefits involved with their participation.
Subsequently, volunteers signed an informed consent form. All procedures were according to the latest version of the Helsinki Declaration.

\section{Measurements}

External load measurements were performed using 10 GPS units (K-GPS ${ }^{\circledR}$, Montelabbate, Italy), at a sampling frequency of $10 \mathrm{~Hz}$, previously used to measure external loads during training and competition ${ }^{23}$. The GPS units were inserted in a specially designed pocket embedded in the back of a sports shirt used by the players. Each unit was activated 15 minutes before starting the data collection period, with a mark at the beginning and end of each measurement session. The external load variables measured were: i) training duration, ii) total distance covered (TD), (considered a global index of the athletes' workload and it is often a stable metric $\left.{ }^{24}\right)$, iii) distance covered in running at 14.4-19.8 km/h (high-intensity distance - HID), iv) distance covered while sprinting (SPD; i.e., $>19.8 \mathrm{~km} / \mathrm{h})^{25}$, v) distance covered in acceleration (ACD; i.e., $>2.5 \mathrm{~m} . \mathrm{s}^{-2}$ ) and deceleration (DECD; i.e., $<-2.5 \mathrm{~m} . \mathrm{s}^{-2}$ ). These locomotor categories are consistent with time-motion analysis of soccer ${ }^{26}$. Data collected were analyzed using the software K-Fitness (K-Sport $^{\circledR}$, Montelabbate, Italy).

\section{Procedures}

Data were collected during 4 consecutive microcycles at the beginning of the 2017-2018 in-season (September and October). The training sessions were categorized as previously suggested ${ }^{15}$, taking into consideration their chronological order before the competition. The first training session of the week (match day plus 1 [MD+1]; Monday) involved aerobicregenerative drills and stretching. The second training session of the week (match day minus 3 [MD-3]; Tuesday) involved neuromuscular training with external loads, circuit training involving movements similar to those of soccer, and small-sided games (i.e., pitch with $50 \mathrm{~m}^{2}$ per player). The third training session of the week (match day minus 2 [MD-2]; Thursday) involved specific-endurance training with small-sided games, using a pitch of $100 \mathrm{~m}^{2}$ per player, with the aim of retaining ball-possession (i.e., no goals were allowed). In addition, a simulated 11 versus 11 matches was played. The fourth training session of the week (match day minus 1 [MD-1]; Friday), near the competition day on Saturday, involved activation drills (i.e., accelerations and ballistic exercises), and tactical drills in preparation for the match on Saturday. The external load of the microcycle (M1, microcycle 1; M2, microcycle 2; M3, microcycle 3; M4, microcycle 4) was obtained by the sum of the values of each variable at each training session (i.e., TD-M1 $=$ MD+1 + MD-3 + MD-2 + MD-1). The external load for the training session corresponds to the mean value of each session for the 4 analyzed microcycles (i.e., $\mathrm{MD}+1=[\mathrm{MD}+1(\mathrm{M} 1)+\mathrm{MD}+1(\mathrm{M} 2)+\mathrm{MD}+1(\mathrm{M} 3)+$ $\mathrm{MD}+1(\mathrm{M} 4)] \div 4)$. The load corresponding to each session was 
expressed in relation to values obtained during competition (i.e., $\% \mathrm{MD}+1=[\mathrm{MD}+1 \times 100] \div$ Oficial Match).

\section{Statistical analysis}

Descriptive results are presented as means \pm standard deviations (SD). Data normality was checked with the ShapiroWilk test. To compare dependent variables between microcicles and between sessions, multivariate analysis of variance (MANOVA) with repeated measures was used, with Bonferroni post hoc and $\alpha$ at $\mathrm{p}<0.05$. In addition, Cohen's $d$ effect size (ES) was used. Ranges for ES analysis was set at $<0.2$ (trivial), 0.2-0.6 (small), 0.6-1.2 (moderate), 1.2-2 (high), and $>2$ (very high) ${ }^{27}$.
Data analysis was completed using the Statistical Package for Social Sciences (SPSS; v. 21.0, SPSS Inc., USA).

Table 1. Time and external load of microcycles and training sessions.

\begin{tabular}{|c|c|c|c|c|c|c|}
\hline & Time (min) & TD (m) & HID (m) & SPD (m) & $\operatorname{ACD}(\mathrm{m})$ & DECD (m) \\
\hline \multicolumn{7}{|l|}{ Microcycles } \\
\hline M1 & $82.15 \pm 7.72$ & $16841 \pm 1770$ & $1798 \pm 641$ & $443 \pm 182$ & $1807 \pm 328$ & $1565 \pm 302$ \\
\hline M2 & $77.42 \pm 7.28$ & $18312 \pm 1491^{\wedge}$ & $2341 \pm 730$ & $606 \pm 242$ & $2032 \pm 375$ & $1771 \pm 326$ \\
\hline M3 & $84.26 \pm 15.71$ & $18574 \pm 1879^{\wedge}$ & $1967 \pm 724$ & $475 \pm 260$ & $1853 \pm 317$ & $1601 \pm 287$ \\
\hline M4 & $71.35 \pm 6.39$ & $12480 \pm 1259$ & $1450 \pm 467$ & $342 \pm 150$ & $1684 \pm 326$ & $1422 \pm 276$ \\
\hline \multicolumn{7}{|l|}{ Sessions } \\
\hline $\mathrm{MD}+1(\mathrm{n}=40)$ & $73.81 \pm 5.11 * *$ & $3814 \pm 616^{* *}$ & $154 \pm 129 * *$ & $45.76 \pm 47.99 * *$ & $393 \pm 144 * *$ & $350 \pm 121 *$ \\
\hline MD-3 $(n=40)$ & $75.81 \pm 6.13 * *$ & $4060 \pm 506 * * \#$ & $406 \pm 228 * *$ & $67.82 \pm 61.17 * *$ & $478 \pm 99$ & $407 \pm 90$ \\
\hline MD-2 (n=40) & $87.7 \pm 17.64$ & $5042 \pm 1312$ & $804 \pm 349$ & $278.1 \pm 135.97$ & $518 \pm 144$ & $456 \pm 125$ \\
\hline MD-1 $(n=40)$ & $77.87 \pm 2.12 * *$ & $4328 \pm 474$ **\# & $429 \pm 167 * *$ & $74.47 \pm 46.72 * *$ & $455 \pm 86$ & $392 \pm 80$ \\
\hline
\end{tabular}

$\mathrm{TD}=$ total distance; HID = high intensity distance $(14-19.8 \mathrm{~km} / \mathrm{h}) ; \mathrm{SPD}=$ sprint distance $(>19.8 \mathrm{~km} / \mathrm{h})$ : ACD = acceleration distance $\left(>2.5 \mathrm{~m} / \mathrm{s}^{2}\right) ;$ DECD $=$ deceleration distance $\left(>-2.5 \mathrm{~m} / \mathrm{s}^{2}\right)$.

$\wedge$ Denote significant differences with M4 ( $<<0.01)$. Denote significant differences with MD-2 $(*$ and $* *, p<0.05$ and $p<0.01$, respectively). "Denote significant differences with MD+1 $\left({ }^{\#}, \mathrm{p}<0.01\right)$.

\section{Training Sessions}

The external loads of the training sessions are indicated in Table 1. A greater $(\mathrm{p}<0.01)$ time, TD, HID and SPD were observed in MD-2 as compared with $\mathrm{MD}+1(\mathrm{ES}=1.07 ; \mathrm{ES}=1.2 ; \mathrm{ES}=2.47 ; \mathrm{ES}=2.28$, MD-3 (ES = 0.9; $\mathrm{ES}=0.99 ; \mathrm{ES}=1.35 ; \mathrm{ES}=1.99)$ and MD-1 (ES $=0.78 ; \mathrm{ES}=0.72 ; \mathrm{ES}=1.37 ; \mathrm{ES}=2)$. Moreover, $\mathrm{TD}$ was greater $(\mathrm{p}<0.01)$ in MD-3 $(\mathrm{ES}=0.44)$ and MD-1 $(\mathrm{ES}=0.94)$ compared with $\mathrm{MD}+1$. In addition, $A C D$ and $D E C D$ were lower $(\mathrm{p}<0.01$ and $\mathrm{p}<0.05$, respectively) in $\mathrm{MD}+1$ than in $\mathrm{MD}-2(\mathrm{ES}=0.87 ; \mathrm{ES}=0.86)$.

\section{External loads during training and official competition}

Figure 1 shows the external loads during training and official matches. In general, a progressive trend was observed for duration and external loads in a given training week from MD+1 toward MD-2, with a reduction in MD-1. Aside from training duration, all external loads variables (TD, $\mathrm{ES}=4.65$ to 39.80 ; $\mathrm{HID}, \mathrm{ES}=4.09$ to 35.10 ; $\mathrm{SPD}, \mathrm{ES}=3.38$ to $48.70 ; \mathrm{ACD}, \mathrm{ES}=4.78$ to $25.20 ; \mathrm{DECD}, \mathrm{ES}=4.90$ to 19.00 ) were lower $(\mathrm{p}<0.05$, Figure $1 \mathrm{~A})$ during training sessions in relation to official match demands. The percentage of HID, in relation to the distance covered during an official match, was lower in $\mathrm{MD}+1$ $(\mathrm{p}<0.01)$ and MD-3 $(\mathrm{p}<0.05)$ compared to $\mathrm{MD}-2(\mathrm{ES}=2.28 ; \mathrm{ES}=1.84$, respectively). Similarly, $\mathrm{SPD}$ in $\mathrm{MD}+1(\mathrm{ES}=3.13), \mathrm{MD}-3(\mathrm{ES}=2.99)$ and MD-1 $(\mathrm{ES}=2.95)$ were lower $(\mathrm{p}<0.01)$ compared to MD-2.

\section{Training Microcycles}

The external loads of each microcycle are indicated in Table 1. The TD was lower $(\mathrm{p}<0.01)$ in M4 compared to M2 $(\mathrm{ES}=4.23)$ and M3 (ES = 3.81). The remaining external load variables (time, HID, SPD, ACD, and DECD) were similar between the four microcycles.

\section{Results}




\section{Accumulated load per microcycle}

Considering 1 as the value associated with official competition, the dependent variable time showed the greatest value (4.5). The TD (2.9), ACD (3.0), and DECD (3.0) showed an accumulated load greater than the mean value of 1 associated with an official competition, while HID (2.1) and SPD (1.9) showed lower values of accumulated load.

\section{Discussion}

The aim of this study was to assess the external load of amateur players during 4 consecutive training microcycles and their corresponding training sessions, in relation to the external load during competition. Results revealed that time and typical daily external training loads (i.e., HID, SPD, ACD, and DECD) did not differ throughout each microcycle. External training loads were significantly greater (i.e., TD, HID and SPD) on MD-2 than in the rest of the training sessions. Aside from training duration, all external loads variables (TD, HID, SPD, ACD, and DECD) were lower during training sessions compared to official matches. However, external load values (especially HID, and SPD) during MD-2 were closer to the external load values observed during official matches when compared to the rest of the training sessions.

The results revealed that time and typical daily external training loads (i.e., HID, SPD, ACD and DECD) did not differ across the microcycles. Similarly, in professional soccer players, the external load did not change over six consecutive in-season microcycles ${ }^{16}$. Although between-microcycle load variations may aid in the preparation of athletes ${ }^{28}$, in soccer, with a high frequency of official matches, the players need to improve their competitive fitness while minimizing fatigue ${ }^{15}$. To this aim, application of between-session load variation within a given microcycle may be a well-suited approach ${ }^{29}$. Besides, reduced changes in the training load across different microcycles seem to be associated with a reduced injury incidence ${ }^{30,31}$ so the load management found in our study seems to be an interesting alternative during competition ${ }^{28}$. In addition, the microcycles analyzed in this study were scheduled at the beginning of the in-season. In this sense, it is possible that the relative lack of external load variation between microcycles at the beginning of the in-season was related to the high-loads usually applied during the preseason $^{32}$. In this case, reducing and maintaining constant the training loads at the beginning of the season can play a role in avoiding excessive fatigue and its deleterious effects over the competition duration ${ }^{33}$.

The analysis of the load of the sessions within the microcycle indicates that TD, HID, and SPD were significantly greater on MD-2 than in the rest of training days (i.e., MD+1, MD-3, and MD-1). Previous studies have already shown this difference in the distribution of loads during the microcycle ${ }^{16,18}$. Such findings support traditional periodization models postulating how training load should vary in order to facilitate optimal physiological adaptation. Previous research has shown how enabling variation among specific training parameters may maximize training adaptations ${ }^{29,34}$. However, a previous study ${ }^{15}$ did not find significant inter-session external load variations for a given microcycle, other than a reduced load during MD-1 sessions. Although some studies observed greater external loads near the beginning of a given microcycle (e.g., MD-3 $>$ MD-2) $)^{15,16,18}$, our results indicated greater external loads during MD-2 compared to the rest of the training sessions of a given microcycle. This difference can be caused by the number of training days that make up the microcycle (4 vs. 5 ) or by the distribution of the loads planned by the $\operatorname{coach}^{21}$.

On the other hand, the lower external load (aside from $\mathrm{MD}+1$ ) was observed in the training sessions immediately before a match day, similar to the results of previous investigations $\mathrm{s}^{15,16,18}$. In comparison with previous work, the average total distance covered was $4311 \mathrm{~m}$, which was in the range of values reported by Gaudino, Alberti, Iaia ${ }^{35}$ $(3618-4133 \mathrm{~m})$. However, the distances covered in both the current study and that of Gaudino et. ${ }^{35}$ fell short in comparison with those reported by Owen, Lago-Peñas, Gómez, Mendes, Della $^{16}(6871 \mathrm{~m})$ and Malone, Di Michele, Morgans, Burgess, Morton, Drust ${ }^{15}(5181 \mathrm{~m})$. This difference can be caused by the level of the participants since in our study we involved amateur and non-professional players.

The aim of the reduced load during MD-1 compared to MD-2 could be to reduce the potential effects of fatigue accumulation ${ }^{15,16}$. This taper strategy might promote greater performance ${ }^{18,19}$, and may be easily applied among professional soccer clubs according to their competitive schedule ${ }^{18}$. However, at the amateur level, adequate taper strategies are difficult to accomplish due to problems associated with jobrelated schedules, family commitments, and amateur-level problems with official match organization, among others.

Training prescription and also the communication between players and the coach may be facilitated when training loads are assessed in relation to official-match related-loads ${ }^{17}$. As in a previous study ${ }^{17}$, our results indicate that the external loads during training days are lower compared to match days, and that match constitutes the main source of loading during a microcycle ${ }^{36}$. As it has been found in professional soccer players, among the different external-load variables during a match, the dependent variable duration is the one with greater value, reaching 4.5 during the microcylce ${ }^{17}$. In our study, the load accumulated in HID, SPD, ACD, and DECD were 2.1, $1.9,3.0$ and 3.0, respectively. It is therefore important to note that in the sum of 4 training sessions (MD+1, MD-3, MD-2, and MD-1), the HID and SPR values corresponding to only one match are replicated during a microcycle. Is possible that the frequent use of small-sided games, which are regarded to the reduced distance, covered at high-speed and sprint ${ }^{32,33}$, may be one of the justifications for these results. According to our results, during MD-3 the use of small-sided games with pitch dimension resulting in $50 \mathrm{~m}^{2}$ per player demanded $22.3 \%$ of HID covered during the match. On the other hand, a simulated 11 versus 11 matches performed in MD-3 elicited $47.7 \%$ of HID covered during the match. Since some amount of displacement at high speed and sprint (i.e., HID and SPD) 
seems to exert a protective effect on soccer players against suffering injuries ${ }^{37}$, it would be necessary to increase this type of actions in training. In addition, during small-sided games, the demands of ACD and DECD are frequent ${ }^{38}$, which justifies the results in the microcycle compared to the match $(\mathrm{ACD}=3.0$ and $\mathrm{DECD}=3.0)$. This stimulus with greater neuromuscular implications should be allocated during the mid-week training days ${ }^{29}$. In this way, it would remain an adequate period of rest before a matchday in order to avoid fatigue effects ${ }^{15}$ that may increase player's injury risk ${ }^{39}$.

The findings of this study show relevant data for amateur players and coaches since it is vital to monitor the imposed training load to know how this pattern can affect performance. This monitoring will allow the coach to more accurately know the load applied to his players in order to apply appropriate tapering strategies and play the match in the best conditions. Some of the main limitations of the study refer to the low number of participants from just one team. In addition, a single type of microcycle has been studied with 6 days between matches. Knowing the dynamics of external loads in longer or shorter weeks could help describe the training and competition demands of amateur soccer players. Finally, knowing the external load both in absolute values and in relative values to the demands of the match in relation to the position occupied by the player would allow comparisons between players.

The data presented here add to the growing body of applied research and provide an alternative perspective when planning and analyzing the distribution of training load within amateur soccer. In conclusion, amateur soccer players from the investigated team present relative stable external training loads across competitive microcycle, with the peak training load observed two days before the match. Besides this, the official match constitutes the highest load during a typical competitive microcycle in this cohort of players.

\section{References}

1. Stolen T, Chamari K, Castagna C,Wisloff U. Physiology of soccer: an update. Sport Med. 2005;35(6):501-536.

2. Djaoui L, Haddad M, Chamari K, Dellal A. Monitoring training load and fatigue in soccer players with physiological markers. Physiol Behav. 2017;181:86-94.

3. Rodriguez-Fernandez A, Sanchez Sanchez J, Rodriguez-Marroyo JA, Casamichana D, Villa JG. Effects of 5-week pre-season smallsided-game-based training on repeat sprint ability. J Sports Med Phys Fitness 2017;57(5):529-536.

4. Faude O, Koch T, Meyer T. Straight sprinting is the most frequent action in goal situations in professional football. J Sports Sci. 2012;30(7):625-631.

5. Borresen J, Lambert MI. The quantification of training load, the training response and the effect on performance. Sports Med. 2009;39(9):779-795.

6. Cummins C, Orr R, O'Connor H, West C. Global positioning systems (GPS) and microtechnology sensors in team sports: a systematic review. Sports Med. 2013;43(10):1025-1042.
7. Buchheit M, Allen A, Poon TK, Modonutti M, Gregson W, Di Salvo V. Integrating different tracking systems in football: multiple camera semi-automatic system, local position measurement and GPS technologies. J Sports Sci. 2014;32(20):1844-1857.

8. Bourdon PC, Cardinale M, Murray A, Gastin P, Kellmann M, Varley MC, Gabbett TJ, Coutts AJ, Burgess DJ, Gregson W, Cable NT.Monitoring Athlete Training Loads: Consensus Statement. Int J Sport Exerc Psychol. 2017;12:161-170.

9. Wallace LK, Slattery KM, Coutts AJ. A comparison of methods for quantifying training load: relationships between modelled and actual training responses. Eur J Appl Physiol. 2014;114(1):11-20.

10. Foster C, Rodriguez-Marroyo JA, de Koning JJ. Monitoring Training Loads: The Past, the Present, and the Future. Int J Sports Physiol Perform. 2017;12:2-8.

11. Bangsbo J, Mohr M, Krustrup P. Physical and metabolic demands of training and match-play in the elite football player. J Sports Sci. 2006;24(7):665-674.

12. Buchheit M. Applying the acute:chronic workload ratio in elite football: worth the effort? Br J Sports Med. 2017;51(18):1325-1327.

13. Aughey RJ. Applications of GPS technologies to field sports. Int J Sports Physiol Perform. 2011;6(3):295-310.

14. Castellano J, Casamichana D, Calleja-Gonzalez J, Roman JS, Ostojic SM. Reliability and Accuracy of $10 \mathrm{~Hz}$ GPS Devices for Short-Distance Exercise. J Sports Sci Med. 2011;10:233-234.

15. Malone JJ, Di Michele R, Morgans R, Burgess D, Morton JP, Drust B. Seasonal training-load quantification in elite English Premier League soccer players. Int J Sports Physiol Perform. 2015;10:489-497.

16. Owen AL, Lago-Peñas C, Gómez M-Á, Mendes B, Dellal A. Analysis of a training mesocycle and positional quantification in elite European soccer players. Int J Sports Sci Coach. 2017;12(5):665-676.

17. Stevens TGA, de Ruiter CJ, Twisk JWR, Savelsbergh GJP, Beek PJ. Quantification of in-season training load relative to match load in professional Dutch Eredivisie football players. Sci Med Footb. 2017;1(2):117-125.

18. Akenhead R, Harley JA, Tweddle SP. Examining the External Training Load of an English Premier League Football Team With Special Reference to Acceleration. J strength Cond Res. 2016;30(9):2424-2432.

19. Zienius MA, Skarbalius A, Zuoza A. Effects of four days of competition modelling followed by six days of tapering on sport performance in junior golfers: a case study. Educ Phys Sport. 2014;2, 63-70.

20. COUNT, FIFA Big. 270 million people active in football. FIFA Communications Division, Information Services, 2007, vol. 31, p. 2007.

21. Burgess DJ. The Research Doesn't Always Apply: Practical Solutions to Evidence-Based Training-Load Monitoring in Elite Team Sports. Int J Sports Physiol Perform. 2017:12, S2136-S2141.

22. Soligard T, Schwellnus M, Alonso J-M, Bahr R, Clarsen B, Dijkstra HP, et al. How much is too much? (Part 1) International Olympic Committee consensus statement on load in sport and risk of injury. Br J Sports Med.2016; 50, 1030-1041

23. Sanchez-Sanchez J, Sanchez M, Hernandez D, Ramirez-Campillo R, Martínez C, Nakamura FY. Fatigue In U12 Soccer-7 Players During Repeated One-Day Tournament Games - A Pilot Study. J strength Cond Res. 2017; July. N.d. 
24. Rampinini E, Bosio A, Ferraresi I, Petruolo A, Morelli A, Sassi A. Match-related fatigue in soccer players. Med Sci Sports Exerc.2011; 43, 2161-2170.

25. Scott BR, Lockie RG, Knight TJ, Clark AC, Janse de Jonge XAK. A comparison of methods to quantify the in-season training load of professional soccer players. Int J Sports Physiol Perform. 2013; 8, 195-202.

26. Bradley PS, Sheldon W, Wooster B, Olsen P, Boanas P, Krustrup P. High-intensity running in English FA Premier League soccer matches. J Sport Sci. 2009; 27, 159-168.

27. Hopkins WG, Marshall SW, Batterham AM, Hanin J. Progressive statistics for studies in sports medicine and exercise science. Med Sci Sports Exerc. 2009;41(1):3-13.

28. Mendez-Villanueva A, Delgado-Bordonau JL. Tactical Periodization: Mourinho's best-kept secret ? Tactical Periodization : a new soccer training approach. Soccer NSCAA J.2012; 3, 28-34.

29. Kelly V, Coutts AJ. Planning and Monitoring Training Loads During the Competition Phase in Team Sports. Strength Cond J.2007; $29,32-37$.

30. Rogalski B, Dawson B, Heasman J, Gabbett TJ. Training and game loads and injury risk in elite Australian footballers. J Sci Med Sport. 2013;16(6):499-503.

31. Gabbett TJ. The training-injury prevention paradox: should athletes be training smarter and harder? Br J Sports Med. 2016;12:1-9.

32. Jeong T-S, Reilly T, Morton J, Bae S-W, Drust B. Quantification of the physiological loading of one week of 'pre-season' and one week of 'in-season' training in professional soccer players. J Sports Sci. 2011;29:1161-1166.

33. Kraemer WJ, French DN, Paxton NJ, Hakkinen K, Volek JS, Sebastianelli WJ. Changes in exercise performance and hormonal concentrations over a big ten soccer season in starters and nonstarters. J Strength Cond Res. 2004;18(1):121-128.

34. Impellizzeri FM, Rampinini E, Coutts AJ, Sassi A, Marcora SM. Use of RPE-based training load in soccer. Med Sci Sports Exerc.2004; 36, 1042-1047.

35. Gaudino P, Alberti G, Iaia FM. Estimated metabolic and mechanical demands during different small-sided games in elite soccer players. Hum. Mov. Sci. 2014: 36, 123-133.

36. Anderson L, Orme P, Di Michele R, Close GL, Morgans R, Drust $\mathrm{B}$, et al. Quantification of training load during one-, two- and three-game week schedules in professional soccer players from the English Premier League: implications for carbohydrate periodisation. J Sports Sci. 2016;34(13):1250-1259.
37. Malone S, Owen A, Mendes B, Hughes B, Collins K, Gabbett TJ. High-speed running and sprinting as an injury risk factor in soccer: Can well-developed physical qualities reduce the risk? J Sci Med Sport. 2018;21(3):257-262.

38. Castellano J, Casamichana D. Differences in the number of accelerations between small-sided games and friendly matches in soccer. J Sport Sci Med. 2013;12(1):209210.

39. Owen AL, Forsyth JJ, Wong P, Dellal A, Connelly SP, Chamari $\mathrm{K}$. Heart rate-based training intensity and its impact on injury incidence among elite-level professional soccer players. J Strength Cond Res. 2015;26(6):1705-1712.

\section{Acknowledgments}

The authors wish to thank: all the subjects and their parents for their participation and commitment to the study.

\section{Corresponding author}

Fabio Y Nakamura

Department of Medicine and Aging Sciences, "G. d'Annunzio" University of Chieti-Pescara, Via dei Vestini, 31, 66100 Chieti, Italy. Email: fabioy_nakamura@yahoo.com.br

Manuscript received on July 4, 2018

Manucript accepted on November 4, 2018

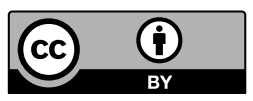

Motriz. The Journal of Physical Education. UNESP. Rio Claro, SP, Brazil - eISSN: 1980-6574 - under a license Creative Commons - Version 4.0 